\title{
ADA's Standards of Medical Care in Diabetes
}

Guidelines from the American Diabetes Association (ADA) describe what should happen with your diabetes care throughout the year. These guidelines are called the Standards of Care. They list what you and your doctor need to do to take care of your diabetes. For example, some things, such as your blood pressure, should be checked every time you see your doctor. Other things, such as a dilated eye exam, should be done once a year.

\section{THE STANDARDS ALSO LIST RECOMMENDED TARGETS FOR YOUR DIABETES ABCs:}

- A: A1C or estimated average glucose (eAG)

- B: blood pressure

- C: blood cholesterol (also called blood lipid) levels

Keeping your diabetes ABCs on track is the most effective way to prevent diabetesrelated health problems.

\section{What should you expect at visits?}

\section{AT EVERY OFFICE VISIT:}

- Talk about your blood glucose meter readings. Take your meter with you.

- Check your blood pressure.

- Check your weight and talk about ways to reach a reasonable weight.

- Talk about what you eat.

- Discuss any lifestyle, work, or emotional changes.

- Discuss your physical activity.

- If you smoke, talk about ways to quit.

- Remove shoes and socks for a foot check.

- Talk about all medicines including over-the-counter pills, herbs, vitamins, or supplements.

- Ask if you should take aspirin to prevent a heart attack.

- Ask any questions you have about your diabetes care.

\section{AT LEAST EVERY 3-6 MONTHS:}

- Check your A1C/eAG.

\section{AT LEAST ONCE A YEAR:}

- Check your cholesterol to see your risk for heart and blood vessel disease.

- Have a dilated eye exam to check for eye problems.

- Get a flu shot.

- Have a complete foot exam.

\section{AT LEAST ONCE IN A LIFETIME:}

- Get a pneumonia vaccine. 